\title{
Expression of glucose transporters in epithelial ovarian carcinoma: Correlation with clinical characteristics and tumor angiogenesis
}

\author{
MIHO TSUKIOKA, YOSHINARI MATSUMOTO, MAIKO NORIYUKI, CHIKA YOSHIDA, \\ HIROYUKI NOBEYAMA, HIROYUKI YOSHIDA, TOMOYO YASUI, \\ TOSHIYUKI SUMI, KEN-ICHI HONDA and OSAMU ISHIKO
}

Department of Obstetrics and Gynecology, Osaka City University Graduate

School of Medicine, 1-4-3 Asahimachi, Abeno-ku, Osaka 545-8585, Japan

Received March 26, 2007; Accepted May 9, 2007

\begin{abstract}
We immunohistochemically examined the expression of the glucose transporters (GLUT)1, GLUT3 and GLUT4, in 154 tumor samples of epithelial ovarian carcinoma. In addition, we investigated the correlations between the expression of GLUTs and the vascular endothelial growth factor (VEGF), and microvessel count and clinical parameters. The rates of expression of GLUT1, GLUT3 and GLUT4 were $98.7 \%, 92.8 \%$ and $84.4 \%$, respectively. GLUT1 and GLUT4 were both strongly expressed in serous adenocarcinoma, but weakly expressed in clear cell adenocarcinoma. The expressions of GLUT1 and GLUT4 correlated with the clinical disease stage. The expressions of GLUT1, GLUT3 and GLUT4 correlated positively with VEGF expression. The expression status for GLUT1, GLUT3, GLUT4 and VEGF did not represent a prognostic factor. These findings suggest that characteristic differences in the patterns of glucose uptake can exist according to the histological type and that GLUT1, GLUT3 and GLUT4 could be related to tumor angiogenesis in epithelial ovarian carcinoma.
\end{abstract}

\section{Introduction}

The major histological types of epithelial ovarian carcinoma are serous, mucinous, endometrioid and clear cell adenocarcinoma. Mucinous and clear cell adenocarcinomas display poor sensitivity to chemotherapy regimens, and thus these histological types show poor prognosis in advanced cases $(1,2)$. In Japan, clear cell adenocarcinoma accounts for a large percentage of epithelial ovarian carcinomas, about $20 \%$, much higher than the approximate $5 \%$ reported in

Correspondence to: Dr Yoshinari Matsumoto, Department of Obstetrics and Gynecology, Osaka City University Graduate School of Medicine, 1-4-3 Asahimachi, Abeno-ku, Osaka 545-8585, Japan E-mail:matsumoyo@med.osaka-cu.ac.jp

Key words: glucose transporter, epithelial ovarian carcinoma, vascular endothelial growth factor, angiogenesis
Europe and the United States. Therefore, therapeutic strategies for advanced ovarian clear cell adenocarcinoma represent a very important issue in Japan. One of the most important pathological features of clear cell adenocarcinoma is the accumulation of glycogen in the cytoplasm (3). Glycogen is synthesized to store glucose. We surmised that this characteristic accumulation of glycogen in ovarian clear cell adenocarcinoma could be related to clinical characteristics. Elucidating the differences in glucose metabolism as a function of the histological type of epithelial ovarian carcinoma and clarifying the relationships between glucose metabolism in the tumor and tumor growth, tumor angiogenesis and metastatic infiltration, would thus provide useful information.

The uptake of glucose into the cells is the first step in glucose metabolism. Glucose in the blood is incorporated into the cells and then metabolized in the glycolytic pathway. Glucose is transported into the cell via facilitative glucose transporters (GLUT). To date, 12 isoforms of GLUT have been identified (4). The up-regulation of the GLUT expression occurs in the transformation process and this increased expression could be a fundamental part of the neoplastic process (5).

The present study immunohistochemically examines the expressions of GLUT1, GLUT3 and GLUT4 in epithelial ovarian carcinomas, and analyzes the correlations between those isoforms and the histological type and clinical stage of the disease. In addition, we investigated the expression of GLUTs and tumor angiogenesis in epithelial ovarian carcinoma. Angiogenesis is essential for tumor growth, thus strongly suggesting that the vascular endothelial growth factor (VEGF) is involved in the angiogenesis of epithelial ovarian carcinoma $(6,7)$. We therefore investigated the relationships among the GLUT expressions, VEGF expression and the microvessel count (MVC) in epithelial ovarian carcinoma. We also analyzed the clinical data, examined the relationships between the GLUTs and the clinical parameters and identified prognostic factors for epithelial ovarian carcinoma.

\section{Materials and methods}

Patients and samples. We studied 154 patients with primary epithelial ovarian carcinoma who underwent surgical resection 
Table I. Patient characteristics.

\begin{tabular}{ll}
\hline Total number of patients & 154 \\
Age mean (range) & $52.7 \pm 11.7$ years $(16-82)$ \\
Histology & \\
$\quad$ Serous & $58(37.7 \%)$ \\
Mucinous & $20(13 \%)$ \\
Endometrioid & $24(15.6 \%)$ \\
Clear cell & $49(31.8 \%)$ \\
Others & $3(1.9 \%)$ \\
Stage & \\
I & $57(37 \%)$ \\
II & $27(17.5 \%)$ \\
III & $63(40.9 \%)$ \\
IV & $7(4.5 \%)$ \\
\hline
\end{tabular}

${ }^{a}$ According to classifications of the International Federation of Gynecology and Obstetrics (FIGO).

at Osaka City University Hospital between March 1994 and April 2005 (Table I). Information regarding the clinical and pathological characteristics of the patient population was obtained from the medical records. All the patients provided written informed consent to participate in the study. According to the criteria of the International Federation of Gynecology and Obstetrics (FIGO), 57 cases were stage I, 27 were stage II, 63 were stage III, and 7 were stage IV. No patients had received chemo- or radiotherapy prior to the tumor sampling. Surgical specimens were obtained from the patients, fixed in $10 \%$ formaldehyde and embedded in paraffin, then cut into $4 \mu \mathrm{m}$-thick sections and mounted on glass slides.

Immunohistochemical analysis. The expressions of GLUT1, GLUT3, GLUT4 and VEGF were investigated in paraffinembedded sections using the avidin-biotin-peroxidase complex method. The paraffin sections were deparaffinized and immersed in 3\% hydrogen peroxidase. Next, an antigen retrieval procedure was performed by microwaving in $10 \mathrm{mM}$ citrate buffer ( $\mathrm{pH} \mathrm{6.0)}$ at $500 \mathrm{~W}$ for $20 \mathrm{~min}$. After washing in phosphate-buffered saline (PBS), the tissue sections were preblocked by $10 \%$ normal goat serum for $15 \mathrm{~min}$. The protocol for the Dako LASB 2 peroxidase kit (Dako, Kyoto, Japan) was followed for each section. The sections were incubated for $60 \mathrm{~min}$ with primary antibodies in a humidity chamber. The primary antibodies comprised of the polyclonal rabbit anti-human GLUT1 antibody (A3536; Dako, Carpinteria, CA, USA), the polyclonal rabbit anti-GLUT3 antibody (AB1345; Chemicon, Temecula, CA, USA), the polyclonal rabbit anti-GLUT4 antibody (AB1346; Chemicon) and the polyclonal rabbit anti-VEGF antibody (Santa Cruz Biotechnology, Santa Cruz, CA, USA). Working dilutions for each primary antibody were 1:200 for anti-GULT1, 1:400 for anti-GLUT3 and GLUT4 and 1:100 for anti-VEGF. The sections were rinsed with PBS for $15 \mathrm{~min}$, and incubated for 10 min with a secondary antibody (biotinylated goat antimouse and rabbit immunoglobulin G secondary antibody; Dako), then incubated with streptavidin-peroxidase complex using 3,3'-diaminobenzidine as a chromogen. Counterstaining was performed using Mayer's hematoxylin. The Specificity of the immunohistochemical reactions was checked by omitting the primary antibody.

Staining analysis. The grade of immunostaining for GLUT1, GLUT3, GLUT4 and VEGF was based on the mean percentage of positive tumor cells determined in 5 areas at x400 magnification as assessed by 3 independent observers. The results were classified as negative (-) when $<5 \%$ of the cells displayed positive staining, weakly positive $(+)$ when $5-50 \%$ were positive, and strongly positive $(++)$ when $>50 \%$ were positive.

Microvessel staining and counting. The avidin-biotinperoxidase complex method was performed using an LASB 2 kit (Dako). The monoclonal mouse anti-CD34 antibody (Zymed Laboratories, San Francisco, CA, USA) was used at 1:200 dilution. Reaction with primary antibodies was incubated for $60 \mathrm{~min}$ in a humidity chamber. For the negative controls, the tissue sections were treated with normal goat serum instead of the primary antibodies.

For microvessel counting, single red-stained cells or clusters of endothelial cells that were clearly separate from adjacent vessels, tumor cells and other connective tissue elements were counted as microvessels. The stained sections were screened at $x 5$ magnification in order to identify the areas of highest vascular density in the tumor, and the vessels were counted at x200 magnification (x20 objective and x10 ocular) in the 5 areas with the highest vascular density. MVC was recorded as the mean number in these 5 areas.

Statistical analysis. The Mann-Whitney U test was computed between the histological subtype and the GLUT 1, GLUT3 and GLUT4 expression. Spearman's rank correlation was computed between the clinical stage and the GLUT 1, GLUT3 and GLUT4 expression. The relationships between VEGF expression and GLUT1, GLUT3 and GLUT4 expression were evaluated by Spearman's rank correlation coefficient. The relationships between MVC and VEGF expression were evaluated using Spearman's rank correlation coefficient.

In this study, age, stage (I-IV), histological type (serous, mucinous, endometrioid and clear cell), and the expression of GLUT1, GLUT3, GLUT4 and VEGF were tested as prognostic factors using Cox's proportional hazard model. Calculations were performed using Statview for Windows version 5.0 software (Abacus Concepts, Berkley, CA, USA). Values are expressed as the means \pm standard deviation, and values of $\mathrm{P}<0.05$ were considered statistically significant.

\section{Results}

Expression of GLUT1. GLUT1 was strongly expressed in the tumor cells. Expression was observed in the cell membrane and cytoplasm, but the nucleus showed no staining for GLUT1. The stroma also showed no staining for GLUT1, whereas the erythrocytes stained positively (Fig. 1A). Positive immunostaining for GLUT1 was observed in $98.7 \%$ of the epithelial ovarian carcinomas (152 of 154). The expression of GLUT1 differed among the histological types, and the difference between serous and clear cell adenocarcinoma was significant 


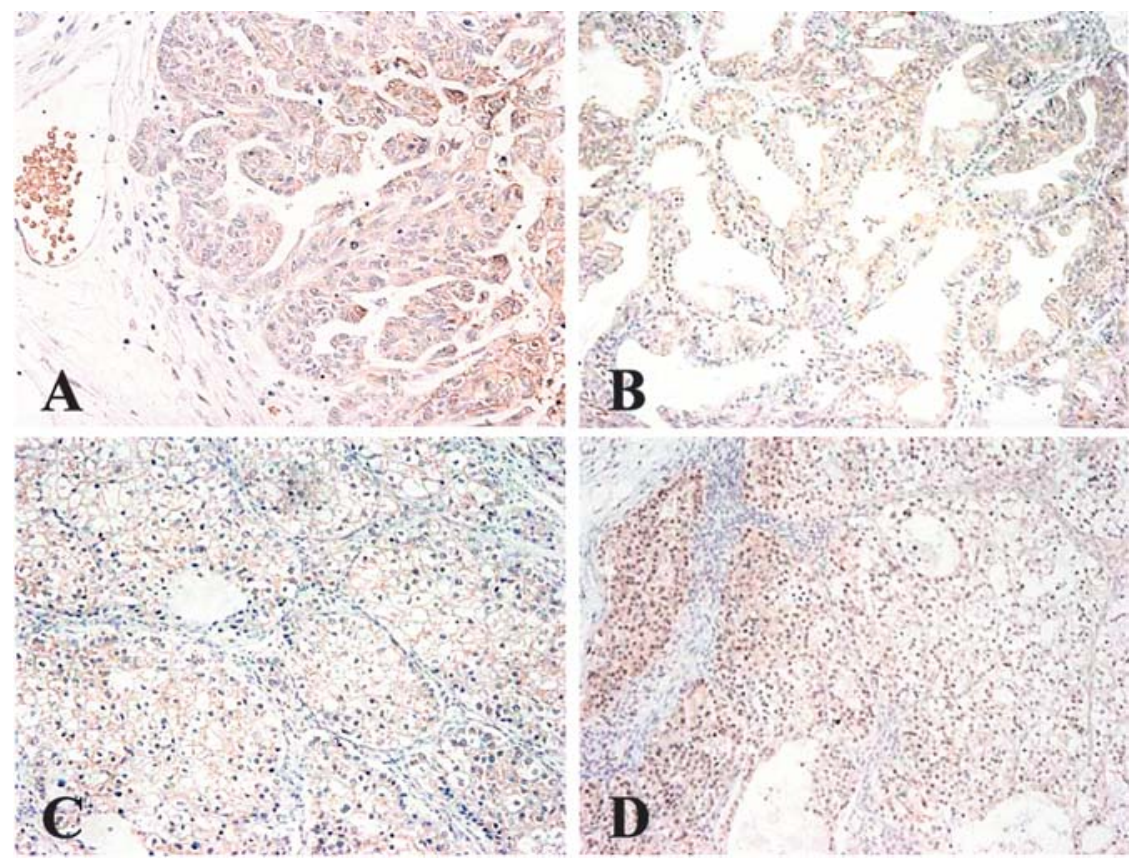

Figure 1. Immunohistochemical staining of GLUT1, GLUT3, GLUT4 and the vascular endothelial growth factor (VEGF) in epithelial ovarian carcinoma. (A) GLUT1 expression in serous adenocarcinoma of the ovary. GLUT1 expression was detected in the cell membrane and cytoplasm of the tumor cells. (B) GLUT3 expression in endometrioid adenocarcinoma of the ovary. GLUT3 expression was detected in the cell membrane and cytoplasm of the tumor cells. (C) GLUT4 expression in clear cell adenocarcinoma of the ovary. GLUT4 expression was detected in the cell membrane, cytoplasm and nucleus of the tumor cells. (D) VEGF expression in clear cell adenocarcinoma of the ovary. VEGF expression was mainly detected in the cell membrane, cytoplasm and nucleus of the tumor cells. Original magnification x200.

Table II. Intensity of GLUT1 staining, histological subtype and FIGO stage.

\begin{tabular}{|c|c|c|c|c|c|}
\hline & Negative & $\begin{array}{l}\text { Weakly } \\
\text { positive }\end{array}$ & $\begin{array}{l}\text { Strongly } \\
\text { positive }\end{array}$ & $\begin{array}{l}\text { Positive } \\
\text { rate }(\%)\end{array}$ & P-value \\
\hline Histology & & & & & $<0.0001^{\mathrm{b}, \mathrm{d}}$ \\
\hline Serous $(n=58)$ & 0 & 1 & 57 & 100 & \\
\hline Mucinous $(n=20)$ & 0 & 1 & 19 & 100 & \\
\hline Endometrioid $(n=24)$ & 0 & 2 & 22 & 100 & \\
\hline Clear cell $(n=49)$ & 2 & 10 & 37 & 95.9 & \\
\hline Others $(n=3)$ & 0 & 0 & 3 & 100 & \\
\hline Stage $^{a}$ & & & & & $0.012^{\mathrm{c}, \mathrm{e}}$ \\
\hline$I(n=57)$ & 2 & 9 & 46 & 96.5 & \\
\hline II $(n=27)$ & 0 & 2 & 25 & 100 & \\
\hline III $(n=63)$ & 0 & 2 & 61 & 100 & \\
\hline IV $(n=7)$ & 0 & 1 & 6 & 100 & \\
\hline Total $(n=154)$ & 2 & 14 & 138 & 98.7 & \\
\hline
\end{tabular}

FIGO, International Federation of Gynecology and Obstetrics. ${ }^{\mathrm{a} A c c o r d i n g}$ to the classifications of FIGO. ${ }^{\mathrm{b}}$ According to the Mann-Whitney U test. 'According to Spearman's correlation coefficient by rank. GLUT1 expression was strongly positive in 138 cases (89.6\%), weakly positive in 14 cases $(9.1 \%)$, and negative in 2 cases $(1.3 \%)$. The expression of GLUT1 differed significantly between the histological types ( ${ }^{\mathrm{d}}$ serous vs clear cell, $\mathrm{P}=0.0003)$. A significant correlation was identified between GLUT1 expression and clinical stage.

$(\mathrm{P}=0.0003)$. GLUT1 expression showed a positive correlation with clinical disease stage $(\mathrm{P}=0.012)$ (Table II). Data analysis by stratification for the histological type revealed a clear positive correlation between GLUT1 expression and disease stage only in serous adenocarcinoma $(\mathrm{P}=0.038$, Spearman's correlation coefficient by rank; data not shown).
Expression of GLUT3. GLUT3 was strongly expressed in the tumor cells. Expression was observed in the cell membrane and cytoplasm, but not in the nucleus or stroma (Fig. 1B). Positive immunostaining for GLUT3 was observed in $92.8 \%$ of the epithelial ovarian carcinomas (143 of 154). The expression of GLUT3 showed no differences among the 
Table III. Intensity of GLUT3 staining, histological subtype and FIGO stage.

\begin{tabular}{|c|c|c|c|c|c|}
\hline & Negative & $\begin{array}{l}\text { Weakly } \\
\text { positive }\end{array}$ & $\begin{array}{l}\text { Strongly } \\
\text { positive }\end{array}$ & $\begin{array}{l}\text { Positive } \\
\text { rate }(\%)\end{array}$ & P-value \\
\hline Histology & & & & & $\mathrm{NS}^{\mathrm{b}}$ \\
\hline Serous $(\mathrm{n}=58)$ & 2 & 8 & 48 & 96.6 & \\
\hline Mucinous ( $n=20)$ & 1 & 2 & 17 & 95 & \\
\hline Endometrioid (n=24) & 3 & 4 & 17 & 87.5 & \\
\hline Clear cell $(n=49)$ & 5 & 6 & 38 & 89.8 & \\
\hline Others $(n=3)$ & 0 & 1 & 2 & 100 & \\
\hline Stage $^{a}$ & & & & & $\mathrm{NS}^{\mathrm{c}}$ \\
\hline $\mathrm{I}(\mathrm{n}=57)$ & 7 & 7 & 45 & 87.7 & \\
\hline II $(n=27)$ & 1 & 2 & 22 & 96.3 & \\
\hline III (n=63) & 3 & 10 & 50 & 95.2 & \\
\hline IV $(n=7)$ & 0 & 2 & 5 & 100 & \\
\hline Total $(n=154)$ & 11 & 21 & 122 & 92.8 & \\
\hline
\end{tabular}

FIGO, International Federation of Gynecology and Obstetrics. NS, not significant. ${ }^{a}$ According to the classifications of FIGO. ${ }^{\mathrm{b}}$ According to the Mann-Whitney U test. ${ }^{c}$ According to Spearman's correlation coefficient by rank. GLUT1 expression was strongly positive in 122 cases (79.2\%), weakly positive in 21 cases (13.6\%), and negative in 11 cases (7.2\%). No significant differences in GLUT3 expression existed between the hisgological types. No significant correlation was found between GLUT3 expression and clinical stage.

Table IV. Intensity of GLUT4 staining, histological subtype and FIGO stage.

\begin{tabular}{|c|c|c|c|c|c|}
\hline & Negative & $\begin{array}{l}\text { Weakly } \\
\text { positive }\end{array}$ & $\begin{array}{l}\text { Strongly } \\
\text { positive }\end{array}$ & $\begin{array}{l}\text { Positive } \\
\text { rate (\%) }\end{array}$ & P-value \\
\hline \multicolumn{6}{|l|}{ Histology } \\
\hline Serous $(n=58)$ & 3 & 3 & 52 & 94.8 & $0.0003^{\mathrm{b}, \mathrm{c}}$ \\
\hline Mucinous $(n=20)$ & 2 & 1 & 17 & 90 & $0.013^{\mathrm{b}, \mathrm{d}}$ \\
\hline Endometrioid $(n=24)$ & 1 & 5 & 18 & 95.8 & $0.021^{\mathrm{b}, \mathrm{d}}$ \\
\hline Clear cell $(n=49)$ & 18 & 5 & 26 & 63.3 & \\
\hline Others $(n=3)$ & 0 & 0 & 3 & 100 & \\
\hline Stage $^{a}$ & & & & & $0.014^{\mathrm{c}, \mathrm{e}}$ \\
\hline $\mathrm{I}(\mathrm{n}=57)$ & 17 & 5 & 35 & 70.2 & \\
\hline II $(n=27)$ & 1 & 2 & 24 & 96.3 & \\
\hline III (n=63) & 5 & 7 & 51 & 92.1 & \\
\hline IV $(n=7)$ & 1 & 0 & 6 & 85.7 & \\
\hline Total $(n=154)$ & 24 & 14 & 116 & 84.4 & \\
\hline
\end{tabular}

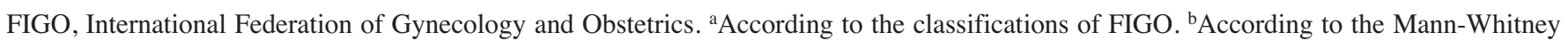
$\mathrm{U}$ test. ${ }^{\mathrm{c}}$ According to Spearman's correlation coefficient by rank. GLUT1 expression was strongly positive in 116 cases (75.3\%), weakly positive in 14 cases $(9.1 \%)$, and negative in 24 cases $(15.6 \%)$. GLUT4 expression differed significantly between the histological types ( ${ }^{\mathrm{d}}$ serous vs clear cell, $\mathrm{P}<0.0001$; mucinous vs clear cell, $\mathrm{P}=0.0132$; endometrioid vs clear cell, $\mathrm{P}=0.0210)$. A significant correlation was identified between GLUT4 expression and clinical stage.

histological types. No correlations were found between GLUT3 expression and clinical disease stage (Table III).

Expression of GLUT4. GLUT4 was strongly expressed in the tumor cells. Expression was observed in the cell membrane, cytoplasm and nucleus. The stroma showed no staining for GLUT4 (Fig. 1C). Positive immunostaining for GLUT4 was observed in $84.4 \%$ (130 out of 154) of the epithelial ovarian carcinomas. GLUT4 expression differed as a function of the histological type, and significant differences in expression existed between clear cell adenocarcinoma and serous, mucinous and endometrioid adenocarcinoma (serous vs clear cell, $\mathrm{P}<0.0001$; mucinous vs clear cell, $\mathrm{P}=0.0132$; endometrioid vs clear cell, $\mathrm{P}=0.0210)$. GLUT4 expression showed a positive correlation with clinical disease stage $(\mathrm{P}=0.014)$ (Table IV). 
Table V. Correlation between VEGF and GLUT1, GLUT3 and GLUT4 expression.

\begin{tabular}{|c|c|c|c|c|c|}
\hline VEGF & Negative & $\begin{array}{l}\text { Weakly } \\
\text { positive }\end{array}$ & $\begin{array}{l}\text { Strongly } \\
\text { positive }\end{array}$ & Total & P-value \\
\hline \multicolumn{6}{|l|}{ GLUT1 } \\
\hline Negative & 2 & 0 & 0 & 2 & \multirow{3}{*}{$0.015^{\mathrm{a}}$} \\
\hline Weakly positive & 1 & 3 & 10 & 14 & \\
\hline Strongly positive & 2 & 13 & 123 & 138 & \\
\hline \multicolumn{6}{|l|}{ GLUT3 } \\
\hline Negative & 2 & 2 & 6 & 11 & \multirow{3}{*}{$0.037^{\mathrm{a}}$} \\
\hline Weakly positive & 1 & 1 & 19 & 21 & \\
\hline Strongly positive & 2 & 12 & 108 & 122 & \\
\hline \multicolumn{6}{|l|}{ GLUT4 } \\
\hline Negative & 4 & 5 & 15 & 24 & \multirow{3}{*}{$0.003^{\mathrm{a}}$} \\
\hline Weakly positive & 0 & 2 & 12 & 14 & \\
\hline Strongly positive & 1 & 9 & 106 & 116 & \\
\hline Total & 5 & 16 & 133 & 154 & \\
\hline
\end{tabular}

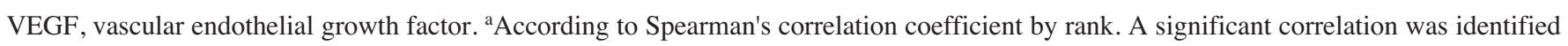
between VEGF expression and GLUT1, GLUT3 and GLUT4 expression.

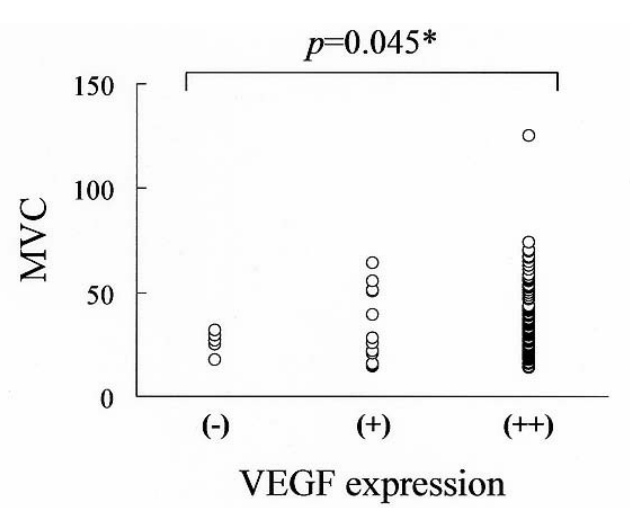

Figure 2. Correlation between microvessel count (MVC) and vascular endothelial growth factor (VEGF) expression. The plot of MVC according to the status of VEGF expression is shown. The status of immunostaining was classified as (-) for $<5 \%$ positive cells, $(+)$ for $5-50 \%$, and $(++)$ for $>50 \%$. The P-value shown indicates the results of the analysis of significance using Spearman's rank correlation coefficient. A significant positive correlation existed between VEGF expression and MVC.

GLUT expression and tumor angiogenesis in epithelial ovarian carcinoma. VEGF was strongly expressed by the tumor cells, in the cytoplasm, cell membrane and nucleus (Fig. 1D). The rate of positive expression of VEGF was $96.7 \%(149 / 154)$. An investigation into the relationships between GLUTs and VEGF expression showed significant positive correlations between the expressions of GLUT1, GLUT3 and GLUT4 and VEGF expression (Table V). VEGF expression also correlated positively with MVC (Fig. 2).

Prognostic factors. Table VI shows the results of Cox's proportional hazard model analysis for the prognostic factors among age, stage, histology (mucinous, endometrioid and clear cell vs. serous adenocarcinoma) and the status of
Table VI. Life table analysis by Cox's proportional hazard model.

\begin{tabular}{lccc}
\hline Covariate & $\begin{array}{c}\text { Partial } \\
\text { regression } \\
\text { coefficient }\end{array}$ & $\begin{array}{l}\text { Odds } \\
\text { ratio }\end{array}$ & P-value \\
\hline Age & 0.040 & 1.041 & $0.0056^{\mathrm{c}}$ \\
Stage & 1.562 & 4.770 & $<0.0001^{\mathrm{c}}$ \\
Histology & & & $0.0312^{\mathrm{c}}$ \\
Mucinous & -0.085 & 0.918 & $0.8954^{\mathrm{b}}$ \\
Endometrioid & 0.771 & 2.161 & $0.1053^{\mathrm{b}}$ \\
Clear cell & 1.335 & 3.799 & $0.0056^{\mathrm{b}, \mathrm{c}}$ \\
GLUT1 $(0,1)^{\mathrm{a}}$ & -0.756 & 0.469 & 0.1833 \\
GLUT3 $(0,1)^{\mathrm{a}}$ & 0.061 & 1.063 & 0.8741 \\
GLUT4 $(0,1)^{\mathrm{a}}$ & 0.544 & 1.724 & 0.1837 \\
VEGF $(0,1)^{\mathrm{a}}$ & -0.581 & 0.560 & 0.1682 \\
\hline
\end{tabular}

VEGF, vascular endothelial growth factor. ${ }^{a} 0$, negative or weakly positive tumors ( $\leq 50 \%$ tumor cells positive); 1 , strongly positive tumors ( $>50 \%$ of tumor cells positive). Not significant, $p \geq 0.05$. The age of the patients, stage (I-IV), histological type (serous, mucinous, endometrioid, clear cell) and the expression of GLUT1, GLUT3, GLUT4 and VEGF were assumed to represent factors affecting prognosis and were assessed using Cox's proportional hazard model. Patient age, stage (I-IV) and histological type were found to correlate with survival time $(\mathrm{p}<0.05)$, but no correlation was identified between the expression of GLUT1, GLUT3, GLUT4 and VEGF.

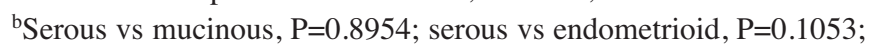
serous vs clear cell, ${ }^{\mathrm{c}} \mathrm{P}=0.0056$

expression for GLUT1, GLUT3, GLUT4 and VEGF. Age, stage and histology were identified as significant prognostic factors. The prognostic factor of histology displayed significant 
differences in the odds ratio between serous and clear cell adenocarcinomas. The expression statuses of GLUT1, GLUT3, GLUT4 and VEGF were not prognostic factors. Analysis of the prognostic factors by the stratification for histological type also revealed that the expressions of GLUT1, GLUT3, GLUT4 and VEGF were not prognostic factors (data not shown).

\section{Discussion}

The proliferation and development of tumor cells requires copious amounts of glucose. GLUTs are necessary for the uptake of glucose by tumor cells, and the most important of these transporters is considered to be GLUT1 (4). Twelve isoforms of GLUT have been identified (5). The present study investigated GLUT1, GLUT3 and GLUT4 among the isoforms that are expressed in the tumor cells of epithelial ovarian carcinoma.

GLUT1 is involved in glucose transport in the basic state (8). Elevated GLUT1 expression has been described in many cancers, including brain, breast, lung, gastrointestinal and ovarian carcinomas $(4,5,9-16)$. Cantuaria et al reported that the expression of GLUT1 is significantly stronger in ovarian serous adenocarcinoma compared with other histological types (13). The present study found that the rate of positive GLUT1 expression varied among the histological types of ovarian carcinoma, being highest in serous adenocarcinoma and lowest in clear cell adenocarcinoma. We thus confirmed that the rate of GLUT1 expression is very high and that GLUT1 plays a major role in the uptake of glucose into the tumor cells of epithelial ovarian carcinoma. In addition, GLUT1 correlated with clinical disease stage and VEGF expression. The proliferative ability of tumor cells has been shown to be significantly higher in serous adenocarcinoma compared with clear cell adenocarcinoma (17). The present results provide a partial explanation for the low proliferative ability of clear cell adenocarcinoma.

GLUT3, like GLUT1, is broadly expressed in the body tissues, and is also thought to be involved in glucose uptake in the basic state (18). GLUT3 is expressed in several tumors such as brain, breast, gastric and ovarian carcinoma (4), and the overexpression of GLUT3 has been identified as a significant indicator of poor prognosis in human non-small cell lung carcinomas $(10,11)$. In the present study, the expression rate of GLUT3 was high and correlated with VEGF expression. These findings indicate that GLUT3 is involved in the glucose uptake by tumor cells and also in tumor angiogenesis. The expression rate of GLUT3 did not differ with the histological type. Staining for GLUT3 is reportedly homogeneously and weakly positive in malignant ovarian tumors, and the expressions are similar even in benign and borderline malignant ovarian tumors (14). These observations suggest that GLUT3 could mediate a pathway of basic transmembranous glucose uptake in ovarian tissue independent of pathological changes.

GLUT4 is mainly expressed in insulin-responsive organs, such as the heart, skeletal muscle and fatty tissue (19). A few studies have investigated the expression in cancer cells such as breast, gastric, lung and ovarian carcinoma, but no correlation was identified with the prognosis of any of these diseases $(4,18,20)$. The present study found that the rate of GLUT4 expression differed among the histological types of ovarian carcinoma, with significantly lower rates in clear cell adenocarcinoma compared with other histological types. In addition, GLUT4 expression showed correlations with VEGF expression, indicating that GLUT4 is involved in tumor angiogenesis. GLUT4 expression also correlated with the clinical stage of disease, but investigation by stratification on the basis of histological type showed no correlations with the disease stage (data not shown). We were unable to elucidate the importance of the finding that the positive expression rate of GLUT4 was particularly lower in clear cell adenocarcinoma. GLUT1 and GLUT4 can thus regulate glucose metabolism via different pathways (20). Further studies regarding the differences in glucose metabolism in different histological types of ovarian carcinoma are warranted.

Angiogenesis is essential for tumor growth, infiltration and the metastasis of solid tumors. The microvessel density of tumors increases in response to various angiogenic factors produced by cancer cells, contributing to the growth of the primary lesion and the ability of the cancer cells to avoid apoptosis and carry out infiltration and metastasis (21). VEGF has been shown to be strongly involved in angiogenesis in epithelial ovarian carcinoma $(6,7,22,23)$. The clinicopathological role of angiogenesis in ovarian carcinoma remains controversial: Some reports have described MVC as a prognostic factor, while other studies have identified no effect on prognosis (22). The present study identified a significant correlation between VEGF expression and MVC. In addition, the expressions of GLUT1, GLUT3 and GLUT4 were found to correlate with VEGF expression. Our findings thus indicate the possibility that GLUT1, GLUT3 and GLUT4 are involved in tumor angiogenesis via the expression of VEGF. The expression of GLUT1 is observed in most malignant tumors, and also correlates with clinical disease stage. Accordingly, GLUT1 plays a primary role in tumor angiogenesis, with GLUT3 and GLUT4 probably playing supporting roles in that process. It is likely that GLUT4 has a certain relationship with the differences in histological type. However, we were unable to demonstrate any unique role for GLUT4 in relation to each of the histological subtypes.

Ovarian carcinomas with strong GLUT1 expression reportedly display a slight tendency toward shorter survival compared to those with weak or no GLUT1 expression, but no significant correlation has been found (14). We applied multivariate analysis in order to examine the prognostic factors in our patient group, showing that the statuses of expression for each of GLUT1, GLUT3, GLUT4 and VEGF did not represent prognostic factors, whereas age, disease stage and histological type did.

In conclusion, the expression of GLUT1 has been reported to be involved in the uptake of glucose by epithelial ovarian carcinoma cells, and the present study determined that the GLUT3 and GLUT4 expressions are also involved. Different histological types of epithelial ovarian carcinoma show characteristic patterns for glucose uptake, and GLUT1 and GLUT4 expressions tend to be lower in clear cell adenocarcinoma. GLUT1, GLUT3 and GLUT4 could also be involved in tumor angiogenesis via the expression of the angiogenic factor VEGF, but the expressions of each of these 
isoforms did not represent prognostic factors. In future, we hope to continue our investigations into the roles of other enzymes in glucose metabolism.

\section{Acknowledgements}

We wish to thank all the gynecologists at Osaka City University Medical School for their support, and Norio Sugimoto (Theranostic Research Institute, Nagoya, Japan) for help with the statistical analyses. This study was supported in part by grants from the Ministry of Education, Culture, Sports and Technology of the Japanese Government.

\section{References}

1. Itamochi H, Kigawa J, Sultana H, Iba T, Akeshima R, Kamazawa S, Kanamori Y and Terakawa N: Sensitivity to anticancer agents and resistance mechanisms in clear cell carcinoma of the ovary. Jpn J Cancer Res 93: 723-728, 2002.

2. Sugiyama T, Kamura T, Kigawa J, Terakawa N, Kikuchi Y, Kita T, Suzuki M, Sato I and Taguchi K: Clinical characteristics of clear cell carcinoma of the ovary: a distinct histologic type with poor prognosis and resistance to platinum-based chemotherapy. Cancer 88: 2584-2589, 2000.

3. Peter Russell: Surface epithelial-stromal tumors of the ovary. In: Blaustein's pathology of the female genital tract. Robert J. Kurman (ed). 4th edition. Springer-Verlag, New York, pp752-762, 1994.

4. Medina RA and Owen GI: Glucose transporters: expression, regulation and cancer. Biol Res 35: 9-26, 2002.

5. Macheda ML, Rogers S and Best JD: Molecular and cellular regulation of glucose transporter (GLUT) proteins in cancer. J Cell Physiol 202: 654-662, 2005.

6. Fujimoto J, Sakaguchi H, Hirose R, Ichigo S and Tamaya T: Biologic implications of the expression of vascular endothelial growth factor subtypes in ovarian carcinoma. Cancer 83: 2528-2533, 1998.

7. Yamamoto S, Konishi I, Mandai M, Kuroda H, Komatsu T, Nanbu K, Sakahara H and Mori T: Expression of vascular endothelial growth factor (VEGF) in epithelial ovarian neoplasms: correlation with clinicopathology and patient survival, and analysis of serum VEGF levels. Br J Cancer 76: 1221-1227, 1997.

8. Fukumoto H, Seino S, Imura H, Seino Y and Bell GI: Characterization and expression of human HepG2/erythrocyte glucose-transporter gene. Diabetes 37: 657-661,1988.

9. Kang SS, Chun YK, Hur MH, Lee HK, Kim YJ, Hong SR, Lee JH, Lee SG and Park YK: Clinical significance of glucose transporter 1 (GLUT1) expression in human breast carcinoma. Jpn J Cancer Res 93: 1123-1128, 2002.
10. Younes M, Brown RW, Stephenson M, Gondo M and Cagle PT: Overexpression of Glut 1 and Glut 3 in stage I nonsmall cell lung carcinoma is associated with poor survival. Cancer 80: 1046-1051, 1997.

11. Ito $T$, Noguchi $Y$, Satoh $S$, Hayashi $H$, Inayama $Y$ and Kitamura $H$ : Expression of facilitative glucose transporter isoforms in lung carcinomas: its relation to histologic type, differentiation grade, and tumor stage. Mod Pathol 11: 437-443, 1998.

12. Noguchi Y, Marat D, Saito A, Yoshikawa T, Doi C, Fukuzawa K, Tsuburaya A, Satoh S and Ito T: Expression of facilitative glucose transporters in gastric tumors. Hepatogastroenterology 46: 2683-2689, 1999.

13. Cantuaria G, Magalhaes A, Penalver M, Angioli R, Braunschweiger P, Gomez-Marin O, Kanhoush R, GomezFernandez C and Nadji M: Expression of GLUT-1 glucose transporter in borderline and malignant epithelial tumors of the ovary. Gynecol Oncol 79: 33-37, 2000.

14. Rudlowski C, Moser M, Becker AJ, Rath W, Buttner R, Schroder W and Schurmann A: GLUT1 mRNA and protein expression in ovarian borderline tumors and cancer. Oncology 66: 404-410, 2004.

15. Cantuaria G, Fagotti A, Ferrandina G, Magalhaes A, Nadji M, Angioli R, Penalver M, Mancuso S and Scambia G: GLUT-1 expression in ovarian carcinoma: association with survival and response to chemotherapy. Cancer 92: 1144-1150, 2001.

16. Smith TA: Facilitative glucose transporter expression in human cancer tissue. Br J Biomed Sci 56: 285-292, 1999.

17. Itamochi H, Kigawa J, Sugiyama T, Kikuchi Y, Suzuki M, and Terakawa N: Low proliferation activity may be associated with chemoresistance in clear cell carcinoma of the ovary. Obstet Gynecol 100: 281-287, 2002.

18. Kayano T, Fukumoto H, Eddy RL, Fan YS, Byers MG, Shows TB and Bell GI: Evidence for a family of human glucose transporter-like proteins. Sequence and gene localization of a protein expressed in fetal skeletal muscle and other tissues. $\mathbf{J}$ Biol Chem 263: 15245-15248, 1988.

19. Rea S and James DE: Moving GLUT4: the biogenesis and trafficking of GLUT4 storage vesicles. Diabetes 46: 1667-1677, 1997.

20. Shibata K, Kajiyama H, Mizokami Y, Ino K, Nomura S, Mizutani S, Terauchi M and Kikkawa F: Placental leucine aminopeptidase (P-LAP) and glucose transporter 4 (GLUT4) expression in benign, borderline, and malignant ovarian epithelia. Gynecol Oncol 98: 11-18, 2005.

21. Folkman J: Clinical applications of research on angiogenesis. N Engl J Med 333: 1757-1763, 1995

22. Deguchi M, Matsumoto $\mathrm{Y}$, Ishiko O and Ogita S: Angiogenesis in ovarian clear cell carcinoma and its relation to endometriosis. Oncol Rep 7: 651-654, 2000.

23. Nakanishi Y, Kodama J, Yoshinouchi M, Tokumo K, Kamimura S, Okuda $\mathrm{H}$ and Kudo T: The expression of vascular endothelial growth factor and transforming growth factor-beta associates with angiogenesis in epithelial ovarian cancer. Int J Gynecol Pathol 16: 256-262, 1997. 